\title{
Enhanced Methane Sorption in Densified Forms of a Porous Polymer Network
}

\author{
Austin C. Kizzie1, Anne Dailly², Lamar Perry'1, Marty A. Lail1, Weigang Lu³, \\ Thomas 0. Nelson', Mei Cai' ${ }^{2}$, Hong-Cai Zhou ${ }^{3}$ \\ ${ }^{1}$ RTI International, Research Triangle Park, USA \\ ${ }^{2}$ General Motors Global Research and Development, Warren, USA \\ ${ }^{3}$ Department of Chemistry, Texas A\&M University, College Station, USA \\ Email: zhou@chem.tamu.edu
}

Received 2 February 2014; revised 14 March 2014; accepted 6 April 2014

Copyright (C) 2014 by authors and Scientific Research Publishing Inc.

This work is licensed under the Creative Commons Attribution International License (CC BY). http://creativecommons.org/licenses/by/4.0/

(c) (†) Open Access

\begin{abstract}
Multi-gram synthesis and densification is presented for a porous polymer network (PPN-4) examined as a possible vehicular methane storage material. Compaction at 17,000 psi doubled the bulk density of the material and unexpectedly increased microporosity within the material. As a result, the densified material exhibits higher excess gravimetric methane uptake and improved total volumetric methane uptake relative to the powder.
\end{abstract}

\section{Keywords}

Adsorbents, Polymers, Methane, Energy, Transportation

\section{Introduction}

The dramatic increase in the production of natural gas over the last decade has led to a substantial reduction in cost of energy derived from this commodity relative to petroleum [1] [2], and as a result, natural gas has become a very attractive fuel for the transportation sector. However, given the relatively low volumetric energy density (VED) of natural gas $\left(0.04 \mathrm{MJ} \cdot \mathrm{L}^{-1}\right.$ at $25^{\circ} \mathrm{C}, 1$ bar) [3] compared to gasoline $\left(34.2 \mathrm{MJ} \cdot \mathrm{L}^{-1}\right)$, [4] [5] natural gas needs to be compressed or liquefied to cryogenic temperatures to improve the energy storage density. Natural gas compressed to 250 bar $(3,600 \mathrm{psi})$ or $\mathrm{CNG}\left(\mathrm{VED}=9.2 \mathrm{MJ} \cdot \mathrm{L}^{-1}\right)$ [4], and natural gas liquefied at $-160^{\circ} \mathrm{C}$ or LNG $\left(\mathrm{VED}=22.2 \mathrm{MJ} \cdot \mathrm{L}^{-1}\right)$ [4] are utilized as fuels in transportation systems where the volume and costs of the fuel storage system are not limiting factors (primarily commercial operations using fleets of trucks and buses). However, utilization of CNG and LNG storage systems in light-duty vehicles has limited market penetration because the fuel tanks are relatively expensive, and occupy a significant amount of cargo space. An alternative 
approach is to utilize porous sorbent materials with an affinity to adsorb methane (and other natural gas species) within a specialized fuel tank. Adsorbed natural gas (ANG) achieves higher VEDs than free natural gas at the same $(P, T)$ operating conditions. In addition, ANG storage can be implemented at temperatures well above LNG, and pressures well below CNG, thereby reducing tank size and minimizing safety hazards.

Several classes of materials have been investigated as potential ANG adsorbents including activated carbons, metal-organic frameworks (MOFs) [4] [6]-[29], covalent organic frameworks (COFs) [30]-[34], as well as porous polymer networks (PPNs) [4] [35]-[39] and other porous polymers [35] [37] [39] [40]-[43]. Although activated carbons exhibit superior chemical stability, it is difficult to execute rational structural design in the development of these materials. The opposite is true for MOFs and COFs, wherein rational design principles have been executed to generate new porous materials with exceptionally high capacities for methane [4] [19] [23]; yet many of these materials suffer from chemical instability, and in some cases structural instability. Rationally designed, high surface area PPNs [36] [38] that exhibit excellent chemical stability, supersede the limitations of the previous generations of porous materials. An example is the porous polymer PPN-4 [36] which exhibits stability in air, exceptionally high Brunauer-Emmett-Teller (BET) surface area of $6461 \mathrm{~m}^{2} \cdot \mathrm{g}^{-1}$, and $0.25 \mathrm{~g} \cdot \mathrm{g}^{-1}$ excess methane adsorption at room temperature and 50 bar. The excess adsorption amount $\left(n_{e x}\right)$ is the only quantity associated with the adsorbed phase directly accessible to measurements. This quantity is defined by the difference, at a given temperature and pressure $(P, T)$, between the amount of adsorbate stored in the porous volume of the adsorbent and the amount that would be present in an identical volume in the absence of adsorbent-adsorbate interactions. The total methane storage $\left(n_{t o t}\right)$ accounts for the total amount of adsorbate molecules present in the bulk volume of the material. The quantity $n_{t o t}$ can be calculated from $n_{\text {ex }}$ according to the following equation:

$$
n_{\text {tot }}=n_{e x}+\rho_{g} \times V_{v}
$$

where $\rho_{g}$ is the density of the bulk gas and $V_{v}$ is the total void volume of the adsorbent. The void volume $V_{v}$ is obtained from the bulk density $\left(\rho_{b}\right)$ and the skeletal density $\left(\rho_{s k e}\right)$ of the adsorbent using:

$$
V_{v}=\left(1 / \rho_{b}\right)-\left(1 / \rho_{\text {ske }}\right)
$$

Considering that the skeletal and bulk densities of an adsorbent can differ by up to an order of magnitude, it is clear that $n_{t o t}$ can be much higher than $n_{e x}$. An oversimplified estimate of material's total adsorption capacity can be made from its excess gravimetric uptake and the material's crystallographic density which excludes all voids that are not a fundamental part of the molecular arrangement. The bulk density should be used instead because it includes the contribution of the particle volume, the interparticle void volume and internal pore volume. Contrary to the crystallographic density the bulk density is not an intrinsic property of the material and it can change depending on how the material is handled.

In brief the total methane storage capacity of the material will naturally depend on the excess amount adsorbed and the amount of macropores and interparticle voids present in the materials, which can vary considerably depending on the processing of the powder. Monolithic or densified adsorbents are needed in many storage applications. As a common industrial practice the adsorbent powders are compacted under external pressure into pellets or monoliths to increase their packing density. The primary objective of the compaction is to minimize the interparticle void volume within powders of adsorbents. Compacting an adsorbent with or without binders affects the porosity and, therefore, the volumetric adsorption capacity. The compaction issue is critical for onboard applications because the space available for the storage tank is limited.

To date, all methane sorption measurements have been performed on PPN-4 in powder form, a form which is impractical for achieving high packing densities in fuel storage vessels. In addition, PPNs reported in the literature are typically prepared at the milligram-scale. An area that deserves further exploration is the scale up of the synthesis of PPNs and other porous polymers [35] [37] [39] [40]-[43] to industrially relevant quantities for vehicular methane storage. Here, we report the first multi-gram scale synthesis of PPN-4, and the methane sorption performance of densified samples of PPN-4.

\section{Results and Discussion}

\subsection{Sample Scale-Up and Pelletization}

To generate gram-scale quantities of PPN-4, it was necessary to begin by scaling up the synthesis of the mono- 
mer, tetrakis(4-bromophenyl)silane. Synthesis of the monomer was achieved by implementing modifications to a previously reported [44] synthetic protocol. Here, 1-bromo-4-iodobenzene was lithiated in anhydrous THF, and the resulting aryllithium was treated with tetraethyl orthosilicate (TEOS) to obtain the monomer (Figure 1 (a)). Recrystallization of the crude material yielded the desired product in $60 \%$ yield.

The successful scale up of tetrakis(4-bromophenyl)silane enabled us to accumulate substantial quantities of monomer needed for gram-scale synthesis of the polymer PPN-4, which is synthesized by Yamamoto polymerization (Figure 1(a) and Figure 1(b)) [36]-[38] [42] [45] [46]. Incremental scaling of the PPN-4 synthesis produced materials with IR spectra consistent with PPN-4 produced at the original scale. A PPN-4 sample synthesized at 32-times the scale of the initial preparation exhibited a BET specific surface area of $4000 \mathrm{~m}^{2} \cdot \mathrm{g}^{-1}$ (calculated [47] from the $\mathrm{N}_{2}$ sorption isotherm measured at $77 \mathrm{~K}$ ). Although the sample exhibited lower surface area than the previously reported value of $6461 \mathrm{~m}^{2} \cdot \mathrm{g}^{-1}$, clearly the Yamamoto polymerization is scalable and can be utilized to generate bulk quantities of high surface area porous polymers. Indeed, over $10 \mathrm{~g}$ of PPN-4 was produced over the course of this study.

As mentioned previously, it is critical that interparticle void volume is minimized in ANG sorbents to maximize the volume of adsorbed methane stored in the system. Therefore, in assessing adsorbent properties for methane storage, the most informative performance metric is the volumetric uptake, denoted by $\left(\mathrm{v}^{\cdot} \mathrm{v}^{-1}\right)$, volume of methane adsorbed per volume of material. This is determined from the ratio of the NTP (Normal Temperature and Pressure defined as gas at $20^{\circ} \mathrm{C}$ and $1 \mathrm{~atm}$ ) volume of the gas to the volume of the adsorbent. PPN-4 was densified by pressing the PPN-4 powder into pellets at $117 \mathrm{MPa}(17,000 \mathrm{psi})$ (Figure 1(c)). The BET surface area of the PPN-4 pellets was $2460 \mathrm{~m}^{2} \cdot \mathrm{g}^{-1}$, a decrease of $38 \%$ relative to the powder. However, bulk density measurements revealed that the pellets exhibited a density of $0.133 \mathrm{~g} \cdot \mathrm{cm}^{-3}$, an $80 \%$ increase relative to the powder.

\subsection{Gas Adsorption and Data Analysis}

Excess methane adsorption at $25^{\circ} \mathrm{C}$ was measured up to 80 bar for the PPN-4 in powder form and densified form (Figure 2). The powder exhibits a lower excess uptake than the reported value for sample synthesized on milligram scale. For instance, the excess methane uptake reaches about $0.15 \mathrm{~g} \cdot \mathrm{g}^{-1}$ at $50 \mathrm{bar}$. This value correlates to the lower BET specific surface area obtained with large scale batch $\left(4000 \mathrm{~m}^{2} \cdot \mathrm{g}^{-1}\right.$ compared to $\left.6461 \mathrm{~m}^{2} \cdot \mathrm{g}^{-1}\right)$. Interestingly, the densified PPN-4 shows a higher gravimetric excess methane uptake than the powder form over the entire measured pressure range.

At first it may seem counterintuitive that the excess gravimetric methane uptake of densified PPN-4 is higher

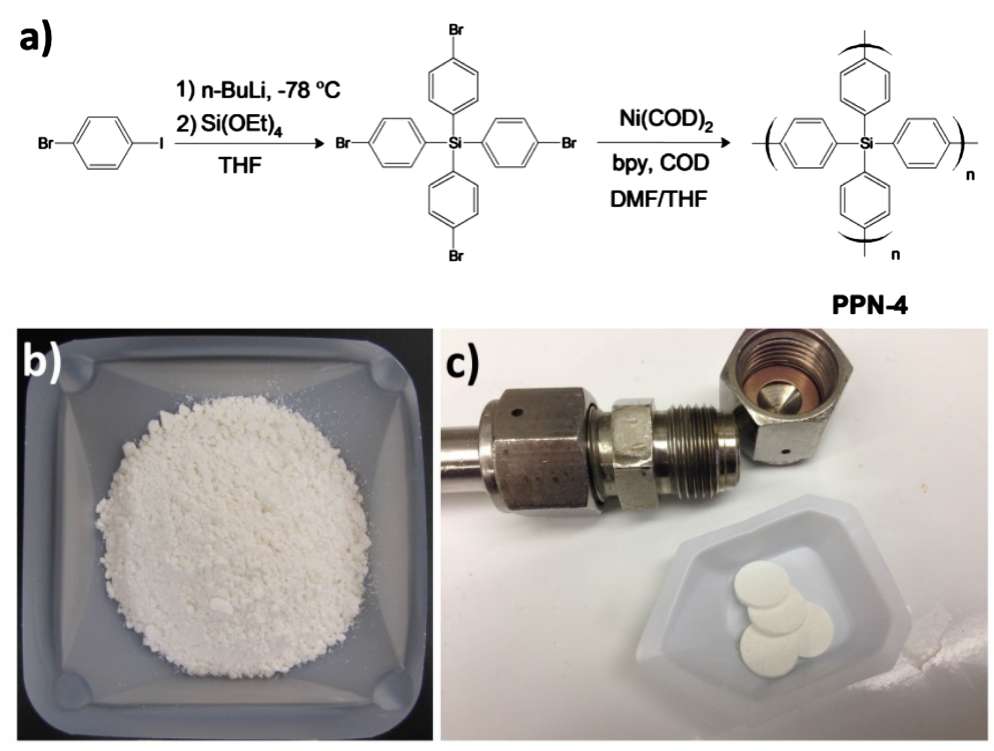

Figure 1. a) Synthetic route to PPN-4; b) PPN-4 powder, after activation; c) Densified form of PPN-4 (pellets). 
than that of PPN-4 powder. At the same $(P, T)$ operating conditions, it may be expected that the lower surface area of the densified PPN-4 pellet would lead to lower methane uptake compared to the higher surface area powder. To gain further insight, pore size distributions in both the powder and densified forms were determined by applying density functional theory to the argon sorption isotherms. For PPN-4 powder, a broad distribution of pores was observed. However, the densified sample of PPN-4 clearly displays a higher fraction of micropores (Figure 3). Although the mechanism for this increase in microporosity is not understood, it is clear that the mechanical compaction at high pressure induces a change in the PPN-4 porosity. Previous studies with activated carbons [3] [48]-[50] have shown that high methane uptake is correlated with high microporosity. In a recent computational study [51] examining the influence of ligand topology on surface properties in porous MOFs, it was found that the optimal range for favorable interaction between methane and surface carbons (the primary elemental constituent in PPN-4) is 3.75 to $4.6 \AA$. This implies that pore widths of 7.5 to $9.2 \AA$ (micropores) are

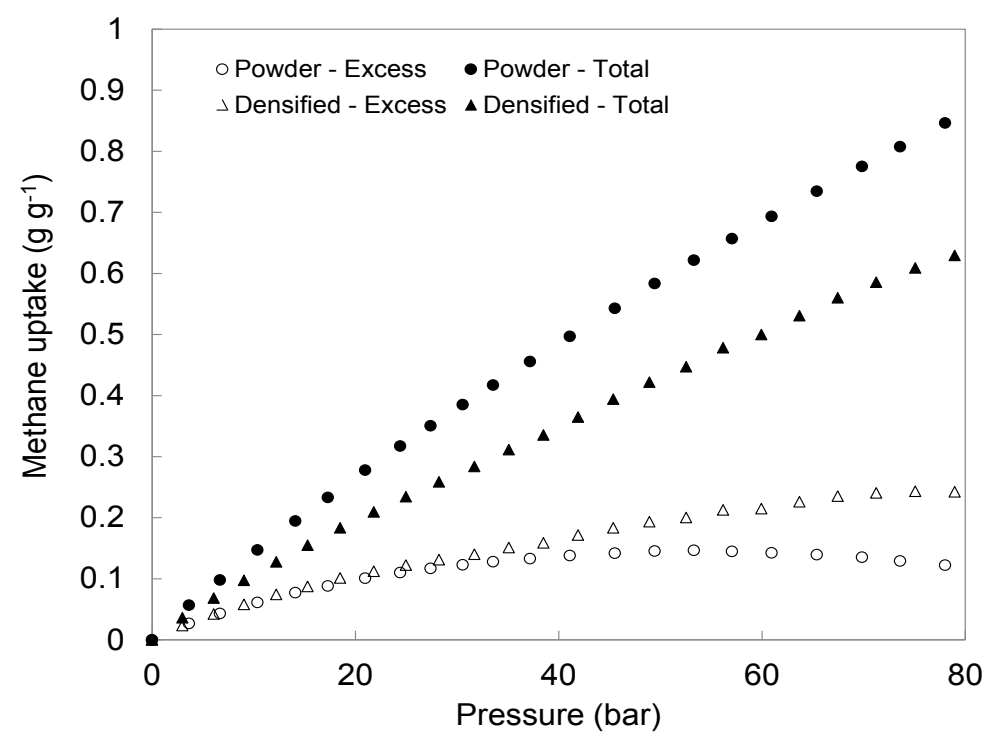

Figure 2. Excess and total gravimetric methane adsorption isotherms for PPN-4 powder and densified PPN-4.

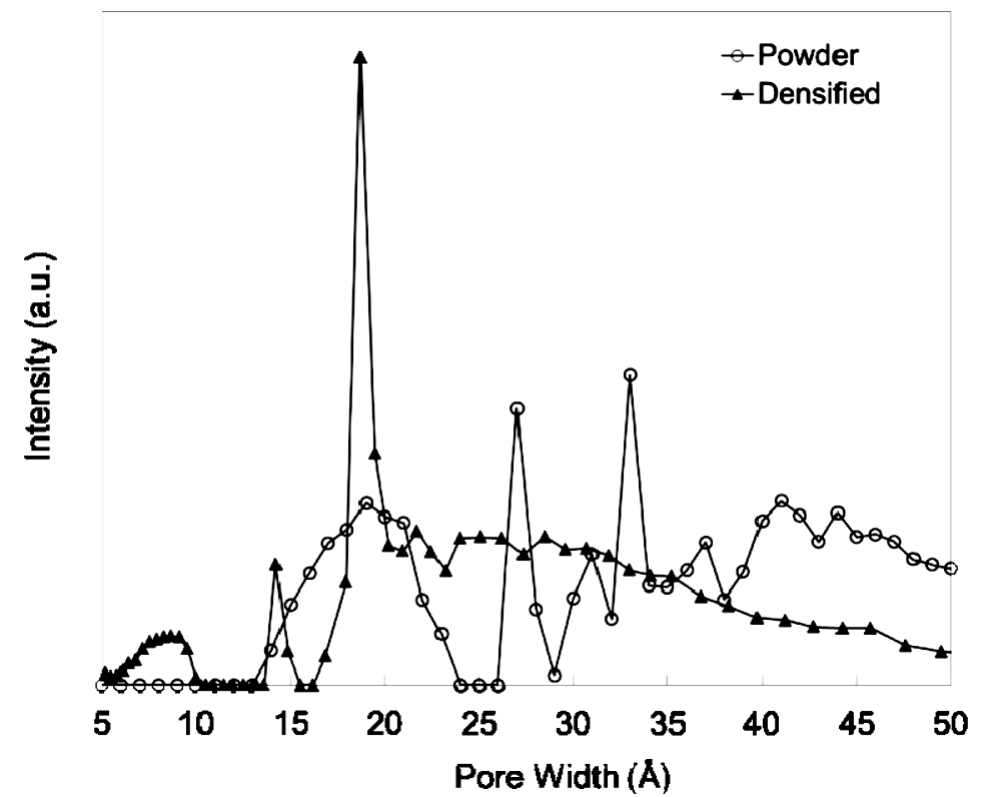

Figure 3. Pore size distribution for PPN-4 powder, and densified PPN-4. 
optimal for high methane uptake. Because the densification of PPN-4 results in an increase in micropores, which are more favorable for high methane uptake, densified PPN-4 outperforms the powder despite having a lower surface area.

The higher gravimetric methane uptake in densified PPN-4 and the higher bulk density lead to improved volumetric methane uptake, as expected from the densification process. The total volumetric adsorption is about 85 $\mathrm{cm}^{3}$ (NTP) $\cdot \mathrm{cm}^{-3}$ at 50 bar compared to $65 \mathrm{~cm}^{3}$ (NTP) $\cdot \mathrm{cm}^{-3}$ for the powder at the same $(P, T)$ conditions (Figure 4). Clearly, densification improves both the excess gravimetric and total volumetric methane sorption performance of PPN-4.

\section{Conclusion}

The volumetric storage capacity of densified PPN-4 shows a larger gain than PPN-4 powder over single gas compression over the entire pressure range examined. However, the methane uptake of densified PPN-4 falls short of the $330 \mathrm{v} \cdot \mathrm{v}^{-1}$ target set by the U. S. Advanced Research Projects Agency-Energy (ARPA-E) for the material because of the relatively low bulk density. These data show that in the development of new porous polymers for vehicular natural gas storage, volumetric methane uptake and bulk density must be assessed. In addition, densification can be utilized to further optimize porosity, and consequently, material performance.

\section{Experimental}

All air sensitive reactions were performed using Schlenk or glove box techniques with oven-dried glassware. THF was distilled over sodium/benzophenone before use. DMF was dried over oven-dried $\mathrm{MgSO}_{4}$ and purged with $\mathrm{N}_{2}$ before use. All other reagents were used as received.

Bulk-scale Synthesis of PPN-4. In a $\mathrm{N}_{2}$ glovebox, an oven-dried 3 L flask equipped with an oven-dried stir bar was loaded with 2,2'-bipyridyl (7.23 g, $46.3 \mathrm{mmol})$, anhydrous DMF $(0.80 \mathrm{~L})$, anhydrous THF $(1.20 \mathrm{~L})$, 1,5-cyclooctadiene $(5.80 \mathrm{~mL}, 5.07 \mathrm{~g}, 46.9 \mathrm{mmol})$, followed by bis(1,5-cyclooctadiene)nickel(0) (12.8 g, 46.5 mmol). After the solids had completely dissolved, tetrakis(4-bromophenyl)silane (6.72 g, $10.3 \mathrm{mmol})$ was added. The resulting mixture was stirred overnight under $\mathrm{N}_{2}$, at room temperature. The mixture was transferred to a $4 \mathrm{~L}$ vessel chilled in an ice bath. Aqueous $6 \mathrm{M} \mathrm{HCl}(320 \mathrm{~mL})$ was slowly added and the resulting mixture was stirred for 6 hours. The solid product was isolated via suction filtration through fritted glass, and the filter cake was washed with $\mathrm{CH}_{3} \mathrm{OH}(\sim 2 \mathrm{~L})$, then water $(\sim 2 \mathrm{~L})$. The solid product was dried in air overnight, then dried under vacuum at $80^{\circ} \mathrm{C}$ for 16 hours to give PPN-4 as a white powder (3.08 g, $\left.9.28 \mathrm{mmol}, 90 \%\right)$.

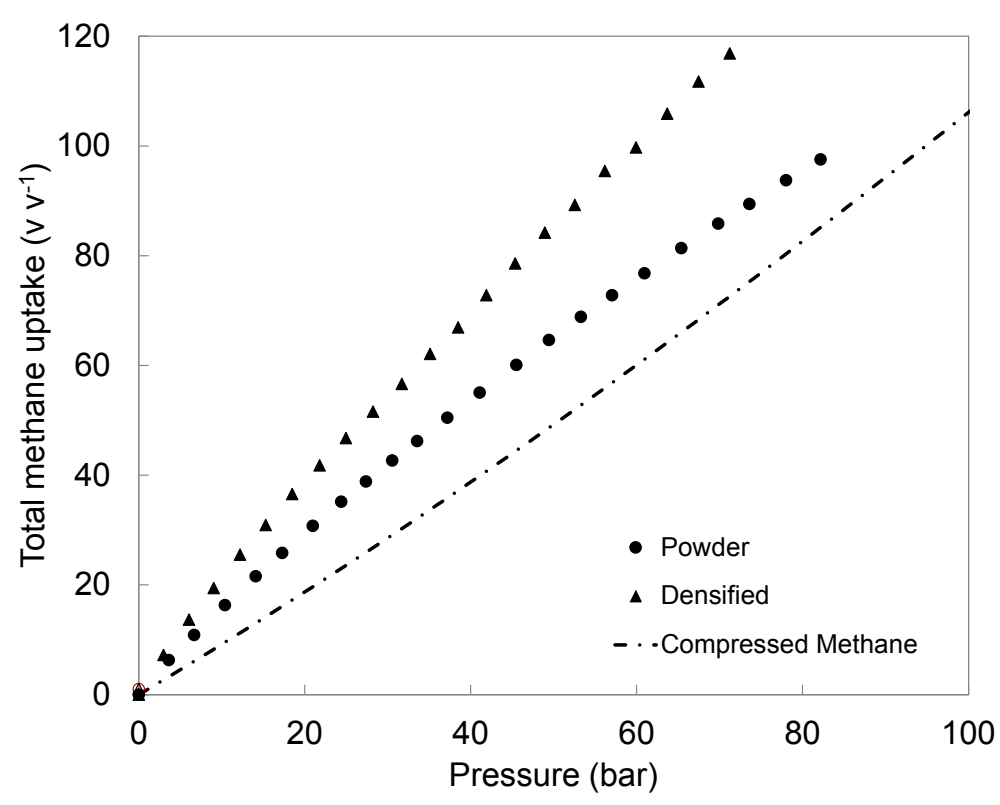

Figure 4. Total methane volumetric adsorption isotherms for PPN-4 powder and densified PPN-4 compared to pure compressed gas. 
Densification of PPN-4. Activated samples of PPN-4 powder (roughly $80 \mathrm{mg}$ per pellet) were loaded into a 13 $\mathrm{mm}$ pellet die (Carver, Inc). The material was pressed at $117 \mathrm{MPa}(17,000 \mathrm{psi})$ to densify PPN-4 in pellet forms. Each pellet was retained for subsequent gas sorption and bulk density measurements.

\section{Acknowledgements}

This work is made possible through the funding support of the United States Department of Energy, Advanced Research Projects Agency-Energy (ARPA-E) under ARPA-E contract DE-AR0000249. The authors thank Dr. Maruthi Sree Pavani for his assistance in monomer preparation.

\section{References}

[1] Tullo, A. (2013) The Shale Gale Revitalizes US Chemical Production. Chemical \& Engineering News, 91, 28-29.

[2] United States Energy Information Administration Annual Energy Outlook (2013) http://www.eia.gov/forecasts/aeo/pdf/0383(2013).pdf

[3] Menon, V.C. and Komarneni, S. (1998) Porous Adsorbents for Vehicular Natural Gas Storage: A Review. Journal of Porous Materials, 5, 43-58. http://dx.doi.org/10.1023/A:1009673830619

[4] Makal, T.A., Li, J.-R., Lu, W. and Zhou, H.-C. (2012) Methane Storage in Advanced Porous Materials. Chemical Society Reviews, 41, 7761-7779. http://dx.doi.org/10.1039/c2cs35251f

[5] United States Department of Energy Alternative Fuels Data Center (2013) http://www.afdc.energy.gov/fuels/fuel properties.php

[6] He, Y., Zhou, W., Yildirim, T. and Chen, B. (2013) A Series of Metal-Organic Frameworks with High Methane Uptake and an Empirical Equation for Predicting Methane Storage Capacity. Energy \& Environmental Science, 6, 2735-2744. http://dx.doi.org/10.1039/c3ee41166d

[7] Konstas, K., Osl, T., Yang, Y., Batten, M., Burke, N., Hill, A.J. and Hill, M.R. (2012) Methane Storage in Metal Organic Frameworks. Journal of Materials Chemistry, 22, 16698-16708. http://dx.doi.org/10.1039/c2jm32719h

[8] Wilmer, C.E., Farha, O.K., Yildirim, T., Eryazici, I., Krungleviciute, V., Sarjeant, A.A., Snurr, R.Q. and Hupp, J.T. (2013) Gram-Scale, High-Yield Synthesis of a Robust Metal-Organic Framework for Storing Methane and Other Gases. Energy \& Environmental Science, 6, 1158-1163.

[9] Peng, Y., Srinivas, G., Wilmer, C.E., Eryazici, I., Snurr, R.Q., Hupp, J.T., Yildirim, T. and Farha, O.K. (2013) Simultaneously High Gravimetric and Volumetric Methane Uptake Characteristics of the Metal-Organic Framework NU-111. Chemical Communications, 49, 2992-2994. http://dx.doi.org/10.1039/c3cc40819a

[10] Peng, Y., Krungleviciute, V., Eryazici, I., Hupp, J.T., Farha, O.K. and Yildirim, T. (2013) Methane Storage in MetalOrganic Frameworks: Current Records, Surprise Findings, and Challenges. Journal of the American Chemical Society, 135, 11887-11894. http://dx.doi.org/10.1021/ja4045289

[11] Lu, Z., Du, L., Tang, K. and Bai, J. (2013) High $\mathrm{H}_{2}$ and $\mathrm{CH}_{4}$ Adsorption Capacity of a Highly Porous (2,3,4)-Connected Metal-Organic Framework. Crystal Growth \& Design, 13, 2252-2255. http://dx.doi.org/10.1021/cg400449c

[12] Getman, R.B., Bae, Y.-S., Wilmer, C.E. and Snurr, R.Q. (2011) Review and Analysis of Molecular Simulations of Methane, Hydrogen, and Acetylene Storage in Metal-Organic Frameworks. Chemical Reviews, 112, 703-723. http://dx.doi.org/10.1021/cr200217c

[13] Feldblyum, J.I., Dutta, D., Wong-Foy, A.G., Dailly, A., Imirzian, J., Gidley, D.W. and Matzger, A.J. (2013) Interpenetration, Porosity, and High-Pressure Gas Adsorption in $\mathrm{Zn} 4 \mathrm{O}(2,6-\text {-naphthalene dicarboxylate })_{3}$. Langmuir, 29, 81468153. http://dx.doi.org/10.1021/la401323t

[14] Guo, Z., Wu, H., Srinivas, G., Zhou, Y., Xiang, S., Chen, Z., Yang, Y., Zhou, W., O’Keeffe, M. and Chen, B. (2011) A Metal-Organic Framework with Optimized Open Metal Sites and Pore Spaces for High Methane Storage at Room Temperature. Angewandte Chemie International Edition, 50, 3178-3181. http://dx.doi.org/10.1002/anie.201007583

[15] Liu, D., Wu, H., Wang, S., Xie, Z., Li, J. and Lin, W. (2012) A High Connectivity Metal-Organic Framework with Exceptional Hydrogen and Methane Uptake Capacities. Chemical Science, 3, 3032-3037. http://dx.doi.org/10.1039/c2sc20601c

[16] Munusamy, K., Sethia, G., Patil, D.V., Rallapalli, P.B.S., Somani, R.S. and Bajaj, H.C. (2012) Sorption of Carbon Dioxide, Methane, Nitrogen and Carbon Monoxide on MIL-101(Cr): Volumetric Measurements and Dynamic Adsorption Studies. Chemical Engineering Journal, 195-196, 359-368. http://dx.doi.org/10.1016/j.cej.2012.04.071

[17] Stoeck, U., Krause, S., Bon, V., Senkovska, I. and Kaskel, S. (2012) A Highly Porous Metal-Organic Framework, Constructed from a Cuboctahedral Super-Molecular Building Block, with Exceptionally High Methane Uptake. Chemical 
Communications, 48, 10841-10843. http://dx.doi.org/10.1039/c2cc34840c

[18] Mu, B. and Walton, K. (2011) Adsorption Equilibrium of Methane and Carbon Dioxide on Porous Metal-Organic Framework Zn-BTB. Adsorption, 17, 777-782. http://dx.doi.org/10.1007/s10450-011-9328-4

[19] Ma, S. and Zhou, H.C. (2010) Gas Storage in Porous Metal-Organic Frameworks for Clean Energy Applications. Chemical Communications, 46, 44-53. http://dx.doi.org/10.1039/b916295j

[20] Wu, H., Simmons, J.M., Liu, Y., Brown, C.M., Wang, X.S., Ma, S., Peterson, V.K., Southon, P.D., Kepert, C.J., Zhou, H.C., Yildirim, T. and Zhou, W. (2010) Metal-Organic Frameworks with Exceptionally High Methane Uptake: Where and How Is Methane Stored? Chemistry-A European Journal, 16, 5205-5214. http://dx.doi.org/10.1002/chem.200902719

[21] Yuan, D., Zhao, D., Sun, D. and Zhou, H.C. (2010) An Isoreticular Series of Metal-Organic Frameworks with Dendritic Hexacarboxylate Ligands and Exceptionally High Gas-Uptake Capacity. Angewandte Chemie International Edition, 49, 5357-5361. http://dx.doi.org/10.1002/anie.201001009

[22] Comotti, A., Bracco, S., Distefano, G. and Sozzani, P. (2009) Methane, Carbon Dioxide and Hydrogen Storage in Nanoporous Dipeptide-Based Materials. Chemical Communications, 2009, 284-286. http://dx.doi.org/10.1039/b820200a

[23] Ma, S., Sun, D., Simmons, J.M., Collier, C.D., Yuan, D. and Zhou, H.C. (2007) Metal-Organic Framework from an Anthracene Derivative Containing Nanoscopic Cages Exhibiting High Methane Uptake. Journal of the American Chemical Society, 130, 1012-1016. http://dx.doi.org/10.1021/ja0771639

[24] Düren, T. and Snurr, R.Q. (2004) Assessment of Isoreticular Metal-Organic Frameworks for Adsorption Separations: A Molecular Simulation Study of Methane/n-Butane Mixtures. The Journal of Physical Chemistry B, 108, 1570315708. http://dx.doi.org/10.1021/jp0477856

[25] Düren, T., Sarkisov, L., Yaghi, O.M. and Snurr, R.Q. (2004) Design of New Materials for Methane Storage. Langmuir, 20, 2683-2689. http://dx.doi.org/10.1021/la0355500

[26] Eddaoudi, M., Kim, J., Rosi, N., Vodak, D., Wachter, J., O’Keeffe, M. and Yaghi, O.M. (2002) Systematic Design of Pore Size and Functionality in Isoreticular MOFs and Their Application in Methane Storage. Science, 295, 469-472. http://dx.doi.org/10.1126/science.1067208

[27] Seki, K. (2001) Design of an Adsorbent with an Ideal Pore Structure for Methane Adsorption Using Metal Complexes. Chemical Communications, 2001, 1496-1497. http://dx.doi.org/10.1039/b104204c

[28] Seki, K. and Mori, W. (2002) Syntheses and Characterization of Microporous Coordination Polymers with Open Frameworks. The Journal of Physical Chemistry B, 106, 1380-1385. http://dx.doi.org/10.1021/jp0130416

[29] Kondo, M., Yoshitomi, T., Matsuzaka, H., Kitagawa, S. and Seki, K. (1997) Three-Dimensional Framework with Channeling Cavities for Small Molecules: $\left\{\left[\mathrm{M}_{2}\left(4,4^{\prime}-\mathrm{bpy}\right)_{3}\left(\mathrm{NO}_{3}\right)_{4}\right] \cdot \mathrm{xH} 2 \mathrm{O}\right\} \mathrm{n}(\mathrm{M}=\mathrm{Co}, \mathrm{Ni}, \mathrm{Zn})$. Angewandte Chemie International Edition, 36, 1725-1727. http://dx.doi.org/10.1002/anie.199717251

[30] Feng, X., Ding, X. and Jiang, D. (2012) Covalent Organic Frameworks. Chemical Society Reviews, 41, 6010-6022. http://dx.doi.org/10.1039/c2cs35157a

[31] Rabbani, M.G., Sekizkardes, A.K., Kahveci, Z., Reich, T.E., Ding, R. and El-Kaderi, H.M. (2013) A 2D Mesoporous Imine-Linked Covalent Organic Framework for High Pressure Gas Storage Applications. Chemistry-A European Journal, 19, 3324-3328. http://dx.doi.org/10.1002/chem.201203753

[32] Furukawa, H. and Yaghi, O.M. (2009) Storage of Hydrogen, Methane, and Carbon Dioxide in Highly Porous Covalent Organic Frameworks for Clean Energy Applications. Journal of the American Chemical Society, 131, 8875-8883. http://dx.doi.org/10.1021/ja9015765

[33] El-Kaderi, H.M., Hunt, J.R., Mendoza-Cortés, J.L., Côté, A.P., Taylor, R.E., O’Keeffe, M. and Yaghi, O.M. (2007) Designed Synthesis of 3D Covalent Organic Frameworks. Science, 316, 268-272. http://dx.doi.org/10.1126/science.1139915

[34] Côté, A.P., Benin, A.I., Ockwig, N.W., O’Keeffe, M., Matzger, A.J. and Yaghi, O.M. (2005) Porous, Crystalline, Covalent Organic Frameworks. Science, 310, 1166-1170. http://dx.doi.org/10.1126/science.1120411

[35] Xiang, Z. and Cao, D. (2013) Porous Covalent-Organic Materials: Synthesis, Clean Energy Application and Design. Journal of Materials Chemistry A, 1, 2691-2718. http://dx.doi.org/10.1039/c2ta00063f

[36] Yuan, D., Lu, W., Zhao, D. and Zhou, H.C. (2011) Highly Stable Porous Polymer Networks with Exceptionally High Gas-Uptake Capacities. Advanced Materials, 23, 3723-3725. http://dx.doi.org/10.1002/adma.201101759

[37] Ben, T., Pei, C., Zhang, D., Xu, J., Deng, F., Jing, X. and Qiu, S. (2011) Gas Storage in Porous Aromatic Frameworks (PAFs). Energy \& Environmental Science, 4, 3991-3999. http://dx.doi.org/10.1039/c1ee01222c

[38] Lu, W., Yuan, D., Zhao, D., Schilling, C.I., Plietzsch, O., Muller, T., Bräse, S., Guenther, J., Blümel, J., Krishna, R., Li, Z. and Zhou, H.C. (2010) Porous Polymer Networks: Synthesis, Porosity, and Applications in Gas Storage/Separation. Chemistry of Materials, 22, 5964-5972. http://dx.doi.org/10.1021/cm1021068 
[39] Farha, O.K., Spokoyny, A.M., Hauser, B.G., Bae, Y.S., Brown, S.E., Snurr, R.Q., Mirkin, C.A. and Hupp, J.T. (2009) Synthesis, Properties, and Gas Separation Studies of a Robust Diimide-Based Microporous Organic Polymer. Chemistry of Materials, 21, 3033-3035. http://dx.doi.org/10.1021/cm901280w

[40] Zhu, Y., Long, H. and Zhang, W. (2013) Imine-Linked Porous Polymer Frameworks with High Small Gas $\left(\mathrm{H}_{2}, \mathrm{CO}_{2}\right.$, $\mathrm{CH}_{4}, \mathrm{C}_{2} \mathrm{H}_{2}$ ) Uptake and $\mathrm{CO}_{2} / \mathrm{N}_{2}$ Selectivity. Chemistry of Materials, 25, 1630-1635. http://dx.doi.org/10.1021/cm400019f

[41] Wood, C.D., Tan, B., Trewin, A., Su, F., Rosseinsky, M.J., Bradshaw, D., Sun, Y., Zhou, L. and Cooper, A.I. (2008) Microporous Organic Polymers for Methane Storage. Advanced Materials, 20, 1916-1921. http://dx.doi.org/10.1002/adma.200702397

[42] Ben, T., Ren, H., Ma, S., Cao, D., Lan, J., Jing, X., Wang, W., Xu, J., Deng, F., Simmons, J.M., Qiu, S. and Zhu, G. (2009) Targeted Synthesis of a Porous Aromatic Framework with High Stability and Exceptionally High Surface Area. Angewandte Chemie International Edition, 48, 9457-9460. http://dx.doi.org/10.1002/anie.200904637

[43] Cooper, A.I. (2009) Conjugated Microporous Polymers. Advanced Materials, 21, 1291-1295. http://dx.doi.org/10.1002/adma.200801971

[44] Fournier, J.H., Wang, X. and Wuest, J.D. (2003) Derivatives of Tetraphenylmethane and Tetraphenylsilane: Synthesis of New Tetrahedral Building Blocks for Molecular Construction. Canadian Journal of Chemistry, 81, 376-380. http://dx.doi.org/10.1139/v03-056

[45] Yamamoto, T., Morita, A., Miyazaki, Y., Maruyama, T., Wakayama, H., Zhou, Z.H., Nakamura, Y., Kanbara, T., Sasaki, S. and Kubota, K. (1992) Preparation of $\pi$-Conjugated Poly(Thiophene-2,5-Diyl), Poly(P-Phenylene), and Related Polymers Using Zerovalent Nickel Complexes. Linear Structure and Properties of the $\pi$-Conjugated Polymers. Macromolecules, 25, 1214-1223. http://dx.doi.org/10.1021/ma00030a003

[46] Yamamoto, T., Ito, T. and Kubota, K. (1988) A Soluble Poly(Arylene) with Large Degree of Depolarization. Poly (2,5-Pyridinediyl) Prepared by Dehalogenation Polycondensation of 2,5-Dibromopyridine with Ni(0)-Complexes. Chemistry Letters, 17, 153-154. http://dx.doi.org/10.1246/cl.1988.153

[47] Walton, K.S. and Snurr, R.Q. (2007) Applicability of the BET Method for Determining Surface Areas of Microporous Metal-Organic Frameworks. Journal of the American Chemical Society, 129, 8552-8556. http://dx.doi.org/10.1021/ja071174k

[48] Alcañiz-Monge, J., De La Casa-Lillo, M.A., Cazorla-Amorós, D. and Linares-Solano, A. (1997) Methane Storage in Activated Carbon Fibres. Carbon, 35, 291-297. http://dx.doi.org/10.1016/S0008-6223(96)00156-X

[49] Sun, J., Rood, M.J., Rostam-Abadi, M. and Lizzio, A.A. (1996) Natural Gas Storage with Activated Carbon from a Bituminous Coal. Gas Separation \& Purification, 10, 91-96. http://dx.doi.org/10.1016/0950-4214(96)00009-6

[50] Cracknell, R.F., Gordon, P. and Gubbins, K.E. (1993) Influence of Pore Geometry on the Design of Microporous Materials for Methane Storage. The Journal Physical Chemistry, 97, 494-499. http://dx.doi.org/10.1021/j100104a036

[51] Martin, R.L. and Haranczyk, M. (2013) Optimization-Based Design of Metal-Organic Framework Materials. Journal of Chemical Theory and Computation, 9, 2816-2825. http://dx.doi.org/10.1021/ct400255c 